\title{
The Influence of Individual Goal Orientation on Innovation Behavior from the Perspective of Knowledge Hiding
}

\author{
Fengqin Cai* \\ School of Business Administration \\ Zhejiang Gongshang University \\ Hangzhou-310018, China \\ *Corresponding author:2450416435@qq.com
}

\author{
Nai Wen \\ School of Business Administration \\ Zhejiang Gongshang University \\ Hangzhou-310018, China \\ vickie_wen@126.com
}

\begin{abstract}
Organizations are increasingly dependent on employees' efforts to innovate. This study investigated 217 employees and used multiple regression statistical methods to explore the impact of different types of goal orientation on employees' innovative behavior(EIB), the mediating role of knowledge hiding $(\mathrm{KH})$ and the moderating role of organizational performance appraisal goal orientation. The results show that: Learning goal orientation(LGO) and Proving goal orientation(PGO) are positively related to innovation behavior, and Avoiding goal orientation(AGO) is negatively related to innovation behavior(IB). Knowledge hiding plays an intermediary role between goal orientation and employees' innovative behavior. Developmental performance appraisal goal orientation(DO) positively moderates the relationship between LGO and IB, in addition, it also positively moderates the relationship between PGO and IB; evaluative performance appraisal goal orientation(EO) negatively moderates the relationship between $L G O$ and IB, as well as it negatively moderates the relationship between PGO and IB.
\end{abstract}

Keywords-individual goal orientation; knowledge hiding; innovation behavior; organizational performance appraisal goal orientation

In the age of knowledge economy, innovation is a key factor that enables companies to adapt to rapid economic changes and gain competitive advantage. In the long run, individual innovation behavior is a key factor in the survival and development of the organization. One option for organizations to become more innovative is to encourage employees to innovate ${ }^{[1]}$. Therefore, this study concerns individual innovation behavior. Recently, scholars have explored the influencing factors of the individual's innovative behavior from the individual characteristic level, among which the goal orientation has been paid widespread attention by scholars. A meta-analysis shows that goal orientation is more likely to predict behavioral performance than cognitive ability and personality traits ${ }^{[2]}$, so goal orientation is the key individual variable that affects employee innovation.

In addition, some scholars explore the path between goal orientation and IB. The organization is operating in an innovative dynamic environment ${ }^{[3]}$, and organizational knowledge is still the main source of innovation. Knowledge sharing acts as a mediator between goal orientation and $\mathrm{EIB}^{[4]}$
But not only knowledge sharing, but also KH may affect the ability of people to work in innovation ${ }^{[5]}$. The "knowledge hiding" behavior has always existed in organizations, but it has long been ignored by the business community and academia. Therefore, recognizing how to reduce the negative effects of $\mathrm{KH}$ is crucial for managers who are striving to cultivate EIB. Based on this, from the knowledge hiding perspective, this study introduces knowledge hiding as a mediator, performance appraisal orientation as a moderator, and further explores the impact mechanism of individual goal orientation on employees' innovation behavior from the perspective of $\mathrm{KH}$.

\section{LITERATURE REVIEW AND HYPOTHESIS}

\section{A. Individual Goal Orientation and Employee Innovation Behavior}

Goal Orientation is a self-development belief that the person perceives, understands and responds to the environment that fulfills his goals, it is an intrinsic feature that is highly relevant to work behavior, work attitude, and job performance ${ }^{[6]}$. Dweck first divided goal orientation into LGO and performance goal orientation ${ }^{[7]}$. With the developing of research, Elloit et al also divided performance goals into performance certification orientation and performance avoidance orientation. This study uses Vandewall's three dimensions: Learning goal orientation, Proving goal orientation, Avoiding goal orientation ${ }^{[8]}$.

EIB refer to employees' intentional efforts to generate, promote and realize innovative ideas in order to benefit work performance, the group or the organization. Scott and Bruce has divided EIB into three stages: Idea generation, seeking support and innovation realization ${ }^{[9]}$. Based on China's situsation, Lu Xiaojun and Zhang Guoliang divide personal IB into two phases: innovative conception and implementation conception $^{[10]}$. The following is the relationship between different dimensions of goal orientation and IB.

Learning-oriented staff attach importance to improving their abilities, so they learn and improve their abilities as much as possible to complete their tasks ${ }^{[11]}$. Employees with LGO focus on mastering new knowledge and new skills, believing that their abilities can be enhanced and having a stronger learning motivation ${ }^{[12]}$. They often process knowledge deeply (including refinement, critical thinking and the integration of 
new and old knowledge and experience) and tend to engage in a more intensive cognitive process when learning new tasks, which lays the foundation for innovation; Secondly, learning goal-oriented employees are more willing to accept challenging and difficult jobs ${ }^{[8]}$, so they are more likely to engage in creative activities from the heart and are more willing to work harder. Therefore, employees with LGO can present innovative ideas at work. Based on this assumption,

H1a: Learning goal orientation is positively related to employee innovation behavior.

PGO refers to the evaluation of self-ability and appreciation from others ${ }^{[8]}$. Proven-oriented employees are vulnerable to external factors such as recognition by others and acceptance of rewards. Through hard work, they focus on outperforming others and aspire to success through hard work ${ }^{[13]}$. Research shows employees with high PGO are more inclined to demonstrate and prove their own abilities and values in front of supervisors and colleagues, such as putting forward new ideas, making better work performance, and actively providing suggestions. This will objectively promote the development of new ideas and team communication and enhance their ability of innovation to a certain extent. Based on this assumption,

H1b: Proving goal orientation is positively relevant to employee innovation behavior.

Relatively speaking, avoidance-orientated individuals believe they are unable to change their capabilities. Employees with AGO desire to evade the challenge and negative evaluation of their abilities. Employees with high AGO first focus on avoiding mistakes or being insufficiently exposed, so they are afraid of accepting challenges and are prone to retreat in the face of difficulties. Therefore, they are reluctant to change the status quo and choose to stick to the rules, which have a negative meaning. Even if there are innovative ideas, they dare not practice or express ideas in innovative activities, so they are often lack of IB in their work. So, based on this assumption,

H1c: Avoidance goal orientation is negatively related to employee innovation behavior.

\section{B. The Mediating Role of Knowledge Hiding}

Connelly first puts forward the concept of knowledge hiding ${ }^{[14]}$, and defines $\mathrm{KH}$ is the intentional attempt to conceal or withhold knowledge others need. The knowledge here mainly includes information, opinions, and professional expertise related to the accomplishment of task performance by the organization members. He further divides it into three aspects: playing dumb, evasive hiding, and rationalized hiding.

Drawing on social exchange theory, knowledge sharing helps employees gain trust and respect, and expands resources through the reciprocity of colleagues ${ }^{[15]}$. Despite the known benefits of knowledge sharing, knowledge sharing also brings inevitable costs, such as extra time and energy ${ }^{[16]}$, so employees may prefer to hide knowledge instead of sharing their knowledge. High learning-oriented employees tend to regard other colleagues as collaborators and view information exchange as a kind of reciprocal behavior. It is believed that sharing valuable knowledge and skills with other colleagues will inevitably lead to their own future access to valuable information from other colleagues. Therefore, for the development of their own ability, employees reduce $\mathrm{KH}$ behavior through performing tasks well. So,it suggests,

$\mathrm{H} 2 \mathrm{a}$ : Learning goal orientation is negatively relevant to knowledge hiding.

In contrast, individuals with PGO want to prove that they perform better than others, and that $\mathrm{KH}$ can be driven by people's desire to achieve higher performance than others ${ }^{[17]}$. Employees with PGO make a strategic choice to exploit their knowledge for their personal benefits and future performance despite its potential detriment to collective performance ${ }^{[18]}$. Moreover, they are sensitive to the loss of information advantage embedded in private knowledge and fear losing competitive advantage due to sharing knowledge. Based on this assumption,

$\mathrm{H} 2 \mathrm{~b}$ : Proving goal orientation is positively related to knowledge hiding.

We expect that employees with avoiding goal orientation tend to hide knowledge because they are anxious that their incompetence may be revealed by sharing irrelevant knowledge. These employees avoid situations that can cause others to notice their own defects because they are vulnerable to external threats to their ego. By choosing to hide their knowledge, employees can avoid potential embarrassing circumstances, such as receiving criticisms that threaten the value of their knowledge ${ }^{[19]}$. Knowledge hiding can be driven by avoiding goal orientation. Based on this assumption,

$\mathrm{H} 2 \mathrm{c}$ : Avoiding goal orientation is positively related to knowledge hiding.

IB is very dependent on information and knowledge sharing [20] and therefore it may be influenced by potential $\mathrm{KH}$. Researchers find that when a colleague perceives other colleagues' $\mathrm{KH}$, the circle of mistrust created by them will impede the creativity of the employees, and we predict that EIB also has a similar relationship pattern. KH drives innovation and implementation more than new ideas because IB also involves promotion, persuasion, and synthesis ${ }^{[22]}$. In this situation, employees are less likely to obtain the information needed to participate in innovation activities, choose among the ideas generated, and provide sufficient support for their innovation implementation. When employees hide knowledge, this may fall them into low interpersonal trust. Recent meta-analysis evidence shows $\mathrm{KH}$ is negatively related to personal innovation ${ }^{[23]}$. Based on this assumption,

H3: Knowledge hiding is negatively related to employees' innovative behavior.

To sum up, different goal orientations may product differences in $\mathrm{KH}$ behavior, and then affect individual IB. Therefore, $\mathrm{KH}$ has an indirect effect between goal orientation and EIB. This study divides the goal orientation into three dimensions. The specific assumptions are:

H4: Knowledge hiding plays a mediating role between learning goal orientation (H4a), proving goal orientation (H4b), avoiding goal orientation $(\mathrm{H} 4 \mathrm{c})$ and employee innovation behavior. 


\section{The Moderating Role of Organizational Performance Appraisal Orientation}

Performance assessment goal orientation refers to the ultimate purpose of using performance appraisal tools perceived by the organization members ${ }^{[24]}$. Meyer et al divide it into development orientation and evaluation orientation ${ }^{[25]}$.

The developmental performance appraisal goal orientation focuses on the employees' future performance, takes employee development as the starting point, helps determine the direction of career development and provides performance feedback through appraisal. It also helps employees analyze their existing deficiencies and improve their knowledge and skills to enhance their capabilities, so that they can adapt to work and improve job performance. Therefore, DO makes employees feel organizational support and help, which helps to form an atmosphere of trust, encourage innovation and freedom in the organization $^{[26]}$. When employees with LGO feel organizational support, it will make greater use of their capabilities and promote IB; they are concerned with outperforming others through their own efforts, while DO could help employees succeed and achieve better performance. Therefore, it encourages employees to increase their IB to some extent. Avoidance-oriented employees are afraid to accept challenge because of fear of negative evaluation, while DO creates a kind of atmosphere tolerating failures for the enterprise, and the appraisal is for better development rather than punishment, so employees are more confidence to innovate. Therefore, hypotheses are made,

H5: The developmental performance appraisal goal orientation will strengthen the positive relationship between learning goal orientation (H5a), proving goal orientation (H5b) and innovation behavior, and weaken the negative relationship between AGO (H5c) and IB.

Evaluative performance assessment goal orientations emphasizes the achievement of performance indicators over a period of time, and view the result as the basis of reward and punishment to decide whether the employee will stay, increase or reduce the salary, etc. In the Chinese culture, employees pay more attention to their superior work performance. Employees with PGO are trying to improve their skills in order to surpass others and express some innovative ideas in their work to product IB. However, they have negative emotions when they suffer setbacks. The early negative feedback will damage the work motivation and later work performance of PGO employees, so the IB will be reduced. Employees with AGO fear negative evaluation, and when they perceive strong performance pressures, they are even more afraid of being punished for failing to meet the appraisal criteria and ultimately reduce IB. It also makes LGO staff focus on performance appraisal, which lacks the internal motivation of innovation and reduces the emergence of IB. So, it suggests,

H6: Evaluative performance assessment goal orientation will weaken the positive relationship between learning goal orientation (H6a) and prove goal orientation (H6b) and innovation behavior, and will increase the negative relationship between avoidance goal orientation (H6c) and innovation behavior.

\section{METHOD}

\section{A. Sample and Data Collection}

To validate the present theoretical framework, we collected data from knowledge workers in Hangzhou, Beijing, Shanghai, and Zhengzhou. The survey questionnaire was divided into three forms: Paper Manuscripts, Word Electronic Manuscripts, and Questionnaire Stars. The survey mainly used the form of questionnaire stars, and meanwhile, word electronic questionnaires were sent by email and paper manuscript questionnaires were issued in the field. The questionnaire was filled out by self-report. The main survey companies include the IT industry, state-owned enterprises, and private enterprises. In this study, a total of 300 questionnaires were distributed, 260 were recovered and a recovery rate was $86.67 \%$. Among them, valid questionnaires were 217 (including 78 paper version questionnaires, 19 electronic questionnaires, and 120questionnaires star). The distribution of effective samples was: the employee sample included $52.5 \%$ female and $47.5 \%$ male; the age was mostly concentrated in the 21-30 years old, accounting for $80.2 \%$ of the total number of samples; undergraduate and higher education accounted for $76.1 \%$ of the total number of samples, college education accounted for $22.1 \%$; employees' working years were mainly concentrated in 1-3 years, accounting for $43.3 \%, 15.7 \%$ in $3-5$ years, and $9.2 \%$ in more than 8 years.

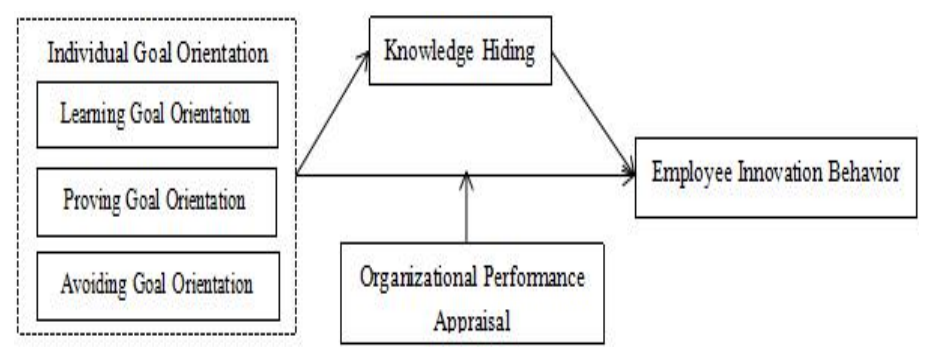

Fig. 1. Research Framework

\section{B. Measures}

Individual goal orientation used the three-dimensional scale developed by VandeWalle ${ }^{[8]}$ for work situations, learning goal orientation's 5 items $(\alpha=0.838)$, proving goal orientation's 4 items $(\alpha=0.810)$ and avoiding goal orientation's four items $(\alpha=0.855)$.

Knowledge hiding was assessed with the 12-item scale developed by Connelly et $\mathrm{a}^{[14]}$, playing dumb, evasive hiding, and rationalized hiding has 4 items separately. Employee innovation behavior was measured with the 6-item scale developed by Scott and Bruce. Performance appraisal orientation was measured with the 9-item scale developed by Liao Jianqiao, which was based on the scale of Cleveland, Murphy and Williams ${ }^{[25]}$, developmental performance appraisal goal orientation's 5 items $(\alpha=0.869)$ and Evaluative performance assessment goal orientation's 4 items $(\alpha=0.804)$. The study used a seven-point Likert scale ranging from one ('strongly disagree') to seven ('strongly agree'). In order to control for demographics, we controlled for gender, age, education, job operation, job years, job nature, and enterprise nature. 


\section{RESULTS}

\section{A. Validity and Reliability}

The reliability and validity of all scales were analyzed using SPSS21.0. The results are shown in Table1. The Cronbach's Alpha coefficients of each scale were all above
0.70 , indicating that each scale has internal consistency. The $\mathrm{KMO}$ values of each scale are more than 0.7 , and the results of Bartlett spherical test are all significant, and the cumulative explanatory variances are more than $50 \%$. The validity test shows that the reliability of the data obtained by the survey is very high.

TABLE I. RELIABILITY AND VALIDITY ANALYSIS $(\mathrm{N}=217)$

\begin{tabular}{lccc}
\hline \multicolumn{1}{c}{ Variables } & Cronbach's Alpha & KMO Values & Cumulative explanatory variances \\
\hline Goal orientation & 0.789 & 0.788 & $65.054 \%$ \\
Knowledge hiding & 0.899 & 0.902 & $73.056 \%$ \\
Innovation behavior & 0.877 & 0.875 & $62.436 \%$ \\
Performance appraisal orientation & 0.737 & 0.818 & $56.618 \%$ \\
\hline
\end{tabular}

\section{B. Descriptive Statistics and Related Analysis}

The mean, standard deviation, and correlation coefficient matrix of the study variables are shown in Table 2 . Table 2 shows that there is a positive correlation between learning, proving goal orientation and innovation behavior $(\mathrm{r}=0.392$ and $0.241, \mathrm{p}<0.01)$, and a negative correlation between avoiding goal orientation, knowledge hiding and innovation behavior $(\mathrm{r}$ $=-0.165$ and $-0.168, \mathrm{p}<0.01$ ), which supports the hypothesis of the model and is suitable for further regression model testing.

TABLE II. MEANS, STANDARD DEVIATIONS, AND CORRELATIONS(N=217)

\begin{tabular}{|c|c|c|c|c|c|c|c|c|}
\hline Variables & $\mathrm{M}$ & SD & 1 & 2 & 3 & 4 & 5 & 6 \\
\hline Learning goal orientation & 5.81 & .905 & - & & & & & \\
\hline Proving goal orientation & 5.31 & 1.123 & $.341^{\star \star}$ & - & & & & \\
\hline Avoiding goal orientation & 2.98 & 1.041 & $-.242^{\star \star}$ & .060 & - & & & \\
\hline Knowledge hiding & 2.94 & 1.213 & $-.116^{\star \star}$ & .005 & $.146^{\star \star}$ & - & & \\
\hline Innovation behavior & 5.27 & .093 & $.392^{\star \star}$ & $.241^{* *}$ & $-.165^{* *}$ & $-.168^{* *}$ & - & \\
\hline DO & 5.16 & 1.069 & $.386^{\star *}$ & $.175^{* *}$ & $-.126^{*}$ & .022 & $410^{* *}$ & \\
\hline $\mathrm{EO}$ & 3.63 & .0897 & -.096 & -.016 & .099 & .060 & -.022 & $-.113^{\star \star}$ \\
\hline
\end{tabular}

\section{Common Method Deviation Test}

This study uses Zhou Hao and Li Ronglong ${ }^{[28]}$ for reference to test the common method deviation. First, the Harman single factor test technique is used to carry out the related statistical test. The specific approach is to put all the items of the questionnaire used in this study into exploratory factor analysis to test the factor analysis without rotation. The principal component analysis extracts 8 common factors. The load of the first principal component is $12.730 \%$, which is not up to the set standard of $40 \%$. Therefore, there is no serious problem of homologous deviation among variables in the study.

\section{Hypothesis Testing}

This paper mainly adopts SPSS21.0 for hierarchical regression analysis. In order to avoid the problem of multicollinearity caused by adding interaction items, independent variables, mediation variables and moderation variables are standardized separately, and then their interaction terms are calculated and brought into the regression equation. The results are shown in Table 3 below.

In Table 3, model 3 shows that learning goal orientation have a significant positive effect on innovation behavior ( $\beta=0.310, p<0.001), \mathrm{H} 1 \mathrm{a}$ is supported, proving goal orientation and IB have a positive effect $(\beta=0.131, \mathrm{p}<0.05), \mathrm{H} 1 \mathrm{~b}$ is established, AGO is negatively related to IB $(\beta=-0.109$, $\mathrm{p}<0.01)$, H1c is supported. From model 1 , we can see that LGO has a negative effect on $\mathrm{KH}(\beta=-0.116, \mathrm{p}<0.05), \mathrm{H} 2 \mathrm{a}$ is supported, PGO and $\mathrm{KH}$ are not significant $(\beta=0.035, \mathrm{p}=0.633)$, so H2b isn't supported, AGO is significantly and positively related to $\mathrm{KB}(\beta=0.146, \mathrm{p}<0.05), \mathrm{H} 2 \mathrm{c}$ is established. Model 4 shows $\mathrm{KB}$ has a negative effect on IB $(\beta-0.167, \mathrm{p}<0.05)$, so H3 is supported. From model 5, DO positively moderates the relationship between $\mathrm{LGO}$ and IB (reciprocal coefficient $\beta=$ $0.498, \mathrm{p}<0.001), \mathrm{H} 5 \mathrm{a}$ is supported. DO also positively moderates the relationship between PGO and IB (reciprocal coefficient $\beta=0.416, p<0.001$ ), H5b is supported. However, DO doesn't moderates negative relationship between AGO and IB (reciprocal coefficient $\beta=0.062, p=0.12$ ), so $\mathrm{H} 5 \mathrm{c}$ is not supported. EO positively moderated the relationship between AGO and IB (interaction coefficient $\beta=0.090, p<0.05$ ), so H6c is supported, EO negatively moderated the relationship between LGO and IB (interaction coefficient $\beta=-0.102$, $\mathrm{p}<0.05$ ), and EO negatively moderated the relationship between PGO and IB (interaction coefficient $\beta=-0.110$, $\mathrm{p}<0.05$ ), so H6a and H6b are established.

We use Edward and Lambert's path analysis method to further examine the indirect effects of knowledge hiding and use the bootstrap method to test the significance of the indirect relation ${ }^{[29]}$. For LGO, the indirect effect of knowledge hiding is 0.02 . The $95 \%$ confidence interval is $[0.0002,0.500]$, it excludes 0 , so which indicates that the mediating effect of $\mathrm{KH}$ on LGO and EIB is significant, so H4a is supported. For PGO, the indirect effect of knowledge hiding is -0.0016 . The $95 \%$ confidence interval is $[-0.0223,-0.0170]$, it excludes 0 , so which indicates knowledge hiding plays an intermediary role between PGO and EIB, so $\mathrm{H} 4 \mathrm{~b}$ is supported. For AGO, the indirect effect of knowledge hiding is -0.0228 . The $95 \%$ confidence interval is $[-0.0627,-0.0041]$, it excludes 0 , so which indicates knowledge hiding plays an intermediary role between AGO and EIB, so $\mathrm{H} 4 \mathrm{c}$ is supported. 
TABLE III. REgRESSION ANALYSIS RESUlTS(N=217)

\begin{tabular}{|c|c|c|c|c|c|}
\hline \multirow[b]{2}{*}{ Variables } & \multicolumn{2}{|c|}{ Knowledge hiding } & \multicolumn{3}{|c|}{ Employees' innovation behavior } \\
\hline & Modell & Mode12 & Model3 & Model4 & Mode15 \\
\hline Gender & -0.183 & -0.183 & -0.136 & -0.157 & -0.147 \\
\hline Age & 0.003 & 0.026 & $0.344^{*}$ & $0.344^{*}$ & $0.366^{*}$ \\
\hline Education & -0.131 & -0.115 & 0.135 & 0.120 & 0.168 \\
\hline Job y ears & -0.009 & 0.009 & -0.051 & -0.052 & -0.015 \\
\hline Operation & 0.212 & 0.168 & -0.092 & -0.067 & -0.151 \\
\hline Job nature & 0.066 & 0.066 & -0.051 & -0.043 & -0.074 \\
\hline Enterprise nature & 0.016 & 0.011 & -0.055 & -0.053 & -0.055 \\
\hline LGO & $-0.116^{*}$ & -0.553 & $0.310 * * *$ & $0.297 * * *$ & 0.233 \\
\hline PGO & 0.035 & 0.010 & $0.131 *$ & $0.135^{*}$ & 0.376 \\
\hline $\mathrm{AGO}$ & $0.146^{*}$ & $0.167^{*}$ & $-0.109 * *$ & -0.093 & -0.186 \\
\hline DO & & $0.003 *$ & & & $0.448 * * *$ \\
\hline EO & & $-0.037 *$ & & & -0.024 \\
\hline $\mathrm{KH}$ & & & & $-0.167^{*}$ & \\
\hline $\mathrm{LGO} \times \mathrm{DO}$ & & & & & $0.498 * * *$ \\
\hline $\mathrm{PGO} \times \mathrm{DO}$ & & & & & $0.416 * * *$ \\
\hline $\mathrm{AGO} \times \mathrm{DO}$ & & & & & 0.062 \\
\hline $\mathrm{LGO} \times \mathrm{EO}$ & & & & & $-0.102 *$ \\
\hline $\mathrm{PGO} \times \mathrm{EO}$ & & & & & $-0.110^{*}$ \\
\hline $\mathrm{AGO} \times \mathrm{EO}$ & & & & & $0.090^{*}$ \\
\hline $\mathrm{R}^{2}$ & $0.037^{*}$ & $0.790^{* *}$ & $0.236^{* *} *$ & $0.248^{*}$ & $0.340 * *$ \\
\hline Ajusted $\mathrm{R}^{2}$ & $0.130 *$ & $0.650 * *$ & $0.199^{*}$ & $0.208 * *$ & $0.280 * *$ \\
\hline
\end{tabular}

Note: ${ }^{*} \mathrm{p}<0.05,{ }^{\star \star} \mathrm{p}<0.01,{ }^{\star \star \star} \mathrm{p}<0.001$.

\section{CONCLUSION AND DISCUSSION}

As organizations operate in increasingly dynamic and fast-paced business environments, their ability to quickly adapt and advance their processes, products, and services have become a key factor for success. So how to motivate and improve the enthusiasm of employees' innovative behavior has always been a key and difficult point in the study of management theory and practice. This study combines the approach of organizational performance assessment with the individual goal orientation and attempts to study the interactive effect between individual traits and organizational practices on employee innovation behavior.

\section{A. Research Conclusion}

First, learning goal orientation and proving goal orientation are positively related to innovation behavior, and avoiding goal orientation and IB is negative; LGO is negatively related to knowledge hiding, and AGO is positively correlated with $\mathrm{KH}$. However, PGO and $\mathrm{KH}$ are irrelevant in this research. It is inconsistent with previous research, the reason may be that: proving goal-oriented individuals seek to maximize reward and minimum punishment, they are responsive to external information, and they use external signs to determine what is appropriate desirable behavior, so they will regard organizational preferences as the main informational basis for choosing favorable behaviors ${ }^{[29]}$. Through interviews with the surveyed organizations, it was found that most surveyed enterprises surveyed integrate knowledge sharing into the management processes such as reward mechanisms, periodic reports, etc. This organizational preference may have contributed to the willingness of proving-oriented employees to spend extra time and effort on knowledge sharing behaviors in pursuit of maximum rewards. $\mathrm{KH}$ plays a mediating role between goal orientation and IB in this study.

Second, DO has positively moderated the relationship between LGO and IB. DO also positively moderates the relationship between PGO and IB. However, DO doesn't moderate the relationship between AGO and IB. The reason is that AGO individuals believe that the ability is innate, but innovation is spontaneous, and the DO hardly affect it. EO negatively moderates the relationship between LGO and IB. EO also negatively moderates the relationship between PGO and IB, this may be because EO will make employees with PGO more concerned with performance and choose conservative work, so that reduce the occurrence of innovation behavior. Last, EO has positively moderated the relationship between $\mathrm{AGO}$ and IB.

\section{B. Practical Implications}

First, managers can take necessary measures to cultivate individual goal orientations, especially learning and proving orientation's employees, such as improving leadership-member relationship, setting learning goals and common awareness. Enhance communication among individuals; improve the sharing of knowledge and skills. Meanwhile, enterprises should select the learning goal-oriented staff to reserve innovative human capital in recruitment, selection, training and organizational reform. And then choose proving orientation employees, because such employees will be innovative advice or ideas in order to surpass others.

Second, leaders can establish the corresponding rules to reward and punish the knowledge behavior of employees in management activities. For employees owning important knowledge to organizational development, the lifelong employment system can be adopted to eliminate their worries and reduce their $\mathrm{KH}$; Establish organizational knowledge files, determine the source of important knowledge of organization, and provide necessary incentive incentives (such as rewards, job promotion.) for individuals who contribute important knowledge to ensure that knowledge contributors can be treated fairly.

Third, improve the existing performance appraisal methods. When formulating a performance appraisal system, companies effectively combine DO and EO. While helping leaders better manage employee performance, they can effectively reduce the 
negative impact of EO on employee innovation, and avoid the negative effect caused by the excessive attention to the past work result or performance of the employee, it is beneficial to enhance employees' internal motivation and increase their enthusiasm for innovation.

\section{Limitations and Future Research}

This study has some limitations. Firstly, the selected sample is not large enough, and more samples will be taken to verify the correctness of results in the future. Secondly, the questionnaire is a self-report method from employees. Although the questionnaires of $\mathrm{KH}$ and innovation are measured after goal orientation and $\mathrm{KH}$, it is also subjective. So it can use pairing for IB and others report knowledge hiding so that the result may be more objective. In addition, it's necessary to explore whether DO and EO exist moderation effect between goal orientation and knowledge hiding. Last, whether there are other moderation variables between goal orientation and innovation behavior remains to be studied.

\section{REFERENCES}

[1] Agarwal U A. Linking justice, trust and innovative work behavior to work engagement[J]. Personnel Review, 2014, 43(1): 41-73.

[2] Payne S C, Youngcourt S S, Beaubien J M. A meta-analytic examination of the goal orientation nomological net[J]. Journal of Applied Psychology, 2007, 92(1): 128-50.

[3] Harari M B, Reaves A C, Viswesvaran C. Creative and innovative performance: a meta-analysis of relationships with task, citizenship, and counterproductive job performance dimensions[J]. European Journal of Work \& Organizational Psychology, 2016(4): 1-17.

[4] KimT,GyeheeL. Hospitality employee knowledge-sharing behaviors in the relationship between goal orientations and service innovative behavior[J]. International Journal of Hospitality Management, 2013, 34(6): 324-337.

[5] The role of multilevel synergistic interplay among team mastery climate, knowledge hiding, and job characteristics in stimulating innovative work behavior[J]. Human Resource Management Journal, 2017, 27(2).

[6] Hong Yan, Wang Duanxu. How leadership behavior and task characteristics stimulate the creativity of knowledge workers: the intermediary role of creative self-efficacy[J]. Soft Science, (In Chinese), 2011, 25(9): 81-85.

[7] Dweck C S. Motivational processes affecting learning[J]. American Psychologist, 1986, 41(10):1040-1048.

[8] Vandewalle D. Development and validation of a work domain goal orientation instrument[J]. Educational \& Psychological Measurement, 1997, 57(6): 995-1015.

[9] Vakulov B G, Samko S G. Bruce, R.A.: Determinants of Innovative Behavior: A Path Model of Individual Innovation in the Workplace[J]. Academy of Management Journal, 1994, 37(3): 580-607.

[10] Lu Xiaojun, Zhang Guoliang. Study on the influence of work motivation on individual innovative behavior[J]. Soft Science, 2007, 21(6): 124-127. (In Chinese)

[11] Anseel F, Beatty A S, Shen W, et al. How are we doing after 30 years? A meta-analytic review of the antecedents and outcomes of feedback-seeking behavior [J]. Journal of Management, 2015, 41(1): $318-348$.
[12] Towler A J, Dipboye R L. Effects of trainer expressiveness, organization, and trainee goal orientation on training outcomes[J]. Journal of Applied Psychology, 2010, 20(1): 65-84.

[13] Elliot A J, Church M A. A hierarchical model of approach and avoidance achievement motivation[J]. Journal of Personality \& Social Psychology, 2004, 72(1): 218--232.

[14] Connelly C E, Zweig D, Webster J et al. Knowledge hiding in organizations[J]. Journal of Organizational Behavior, 2012, 33(1): 64-88.

[15] Flynn F J. How Much Should I Give and How Often? The Effects of Generosity and Frequency or Favor Exchange on Social Status and Productivity[J].Academy of Management Journal, 2003, 46(5): 539-553.

[16] Klotz A C, Bolino M C. Citizenship and counterproductive work behavior: A moral licensing view[J]. Academy of Management Review, 2013, 38(2):292-306.

[17] Rhee Y W, Choi J N. Knowledge management behavior and individual creativity: Goal orientations as antecedents and in - group social status as moderating contingency[J]. Journal of Organizational Behavior, 2017, 38 .

[18] Hendron M G, Oldroyd J B. Withholding the Ace: The Individual- and Unit-Level Performance Effects of Self-Reported and Perceived Knowledge Hoarding[J]. Organization Science, 2015, 26(2): 494-510.

[19] Bordia P. Differences in sharing knowledge inter-personally and via databases: The role of evaluation apprehension and perceived benefits[J]. European Journal of Work \& Organizational Psychology, 2006, 15(3): 262-280.

[20] Schuh S C, Zhang X A, Morgeson F P, et al. Are you really doing good things in your boss's eyes? Interactive effects of employee innovative work behavior and leader-member exchange on supervisory performance ratings[J]. Human Resource Management, 2018, 57(1).

[21] Baer M. Putting Creativity to Work: The Implementation of Creative Ideas in Organizations[J]. Academy of Management Journal, 2012, 55(5): 1102-1119.

[22] Baer M, Evans K, Oldham G R, et al. The social network side of individual innovation: A meta-analysis and path-analytic integration[J]. Organizational Psychology Review, 2015, 5(3): 493-508.

[23] Cleveland J N, Murphy K R, Williams R E. Multiple uses of performance appraisal: Prevalence and correlates[J]. Journal of Applied Psychology, 1989, 74(1): 130-135.

[24] Findley H M, Giles W F, Mossholder K W. Performance appraisal process and system facets: Relationships with contextual performance[J] Journal of Applied Psychology, 2000, 85(4): 634.

[25] Liao Jianqiao, Wen Peng, Wang Zengyan. From settling accounts in the late autumn to pointing out the maze: the strategic shift of performance management[J]. China's Human Resources Development, 2010(2): 67-70. (In Chinese)

[26] Wang Yanzi, Luo Jinlian. The Influence of Goal Orientation on Staff's Innovation Behavior -Based on the Intermediated Effect of Knowledge Sharing. Science and Technology Management, 2011, 32(5): 164 -169 . (In Chinese)

[27] Zhou Hao, Li ronglong. Statistical test and control method of common method deviation[J]. Progress in Psychological Science, 2004, 12: 942-950. (In Chinese)

[28] Edwards J R, Lambert L S. Methods for integrating moderation and mediation: a general analytical framework using moderated path analysis[J]. Psychological Methods, 2007, 12(1):1.

[29] Ma Jun, Zhang Haomin, Yang Tao. Achievement goal-oriented, team performance control on the cross-level impact of employee creativity $[\mathrm{J}]$ Psychology, 2015, 47(1): 79-92. (In Chinese) 